\title{
EMPRÉSTIMO DE LIVROS ELETRÔNICOS, REDES SOCIAIS E A PROTEÇÃO DE DADOS DOS USUÁRIOS
}

\section{LOAN OF DIGITAL BOOKS, SOCIAL NETWORKS AND USERS' DATA PROTECTION}

Liliana Giusti Serra ${ }^{1}$

RESUMO: o artigo discorre sobre a questão da proteção de dados e privacidade dos usuários nas bibliotecas a partir do empréstimo de livros eletrônicos realizado pela parceria OverDrive-Amazon e o uso de redes sociais. É realizado um breve panorama dos normativos relativos à confidencialidade de dados por parte das bibliotecas nos Estados Unidos, países da Europa e a situação brasileira. Finaliza discorrendo sobre a importância da utilização de livros eletrônicos e redes sociais pelas bibliotecas, ressaltando apenas que esse uso seja realizado garantindo a preservação e confidencialidade dos dados pessoais dos usuários, utilizando-se das informações coletadas, mas revertendo-as em ofertas de serviços e divulgação dos acervos.

PALAVRaS-ChaVE: Livros eletrônicos. Proteção de dados dos usuários. Redes sociais. Privacidade. Big data

ABSTRACT: the article discusses the issue of data protection and privacy of patrons in libraries from lending e-books performed by OverDrive-Amazon partnership and the use of social networks. A brief overview of the normative regarding confidentiality of data by libraries in the United States, European countries and the Brazilian situation is realized. Concludes by addressing the importance of using e-books and social networks by libraries, noting only that its application is carried out ensuring the preservation and confidentiality of patrons personal data, using the information collected, but reversing them into service offerings and dissemination of collections.

KEYWORDS: E-books. Patron data protection. Social networks. Privacy. Big data.

\footnotetext{
${ }^{1}$ Mestranda em Programa de Pós-Graduação em Ciência da Informação na Universidade de São Paulo, na Escola de Comunicações e Artes - ECA/USP. Especialista em Gerência de Sistemas pela Fundação Escola de Sociologia e Política de São Paulo (FaBCI/FESPSP). Profissional da informação da Prima (SophiA Biblioteca). Experiência nas áreas de automação, gestão de acervos, gerenciamento de documentação eletrônica, bibliotecas e conteúdos digitais. Igiustiserra@gmail.com

Submetido em: 27/12/2013 - Aceito em: 29/09/2014
} 


\section{INTRODUÇÃ̃o}

A utilização de livros eletrônicos em bibliotecas vem se consolidando gradativamente, com o mercado norte-americano sentindo-se fortalecido, com ofertas de fornecedores e com vislumbres de flexibilidade adicional nas negociações. Paralelamente, a demanda dos usuários em utilizar livros eletrônicos é crescente, não se restringindo ao âmbito de bibliotecas acadêmicas, mas expandindo-se para bibliotecas públicas, justamente as que o mercado editorial demonstrava maior resistência em atender. Na medida em que os modelos de negócios e as atividades desempenhadas por bibliotecas e fornecedores de livros eletrônicos são alinhados e tornam-se mais claros, abre-se espaço para negociação e flexibilização de regras, até então, muito restritivas. As bibliotecas públicas norteamericanas encontraram restrições para inclusão de livros eletrônicos em seus acervos, fator esse decorrente do receio de editores que, ao disponibilizar um livro eletrônico no catálogo da internet da biblioteca (OPAC - Online Public Access Catalogue), temiam que o mesmo poderia ser consultado por qualquer pessoa que entrasse no site. Algumas posturas de editoras foram rigorosas, como o caso da Random House que aumentava os custos de livros eletrônicos em até 300\% quando o comprador era uma biblioteca (RANDOM, 2012), ou a Harper Collins que estabeleceu que quando uma biblioteca adquirisse um livro eletrônico, o mesmo poderia ser utilizado por apenas 26 vezes e, após atingir esse número, um novo livro eletrônico deveria ser comprado (MISENER, 2011). Essa era a quantidade de acessos que o editor estipulou, imaginando que seria o número de vezes que um livro tradicional suportaria ser emprestado. Já a Penguin Books chegou a recusar-se a vender livros eletrônicos para bibliotecas (JOHNSON, 2012). Atualmente ainda existem restrições como a quarentena prazo que um lançamento é liberado para venda no formato digital para bibliotecas -, mas o mercado editorial tem se mostrado mais confiante da possibilidade de utilização de livros eletrônicos em bibliotecas públicas de forma segura.

O anúncio da parceria da OverDrive, distribuidor de livros eletrônicos dos Estados Unidos, com a Amazon, líder em comércio eletrônico, em 2011, foi recebido com expectativa pelas bibliotecas, na certeza de ampliar e flexibilizar o acesso aos livros eletrônicos através de modelos de negócios praticados pelo fornecedor - assinatura e patron driven acquisition (PDA), principalmente - proporcionando amplo acesso a títulos aos usuários de bibliotecas públicas norte-americanas. 
O OverDrive é uma empresa distribuidora de publicações digitais (e-books, audiobooks, música, vídeo etc.), fundada em 1986, com sede no Estado de Ohio. Sua atuação em bibliotecas públicas se iniciou em 2002 e atualmente possui mais de 1.800 .000 títulos digitais, para todas as faixas etárias de público. Nesse conjunto estão representados mais de 1.000 editores, em 64 idiomas, em todas as áreas do conhecimento, além de best sellers. Conta com uma carteira de clientes com mais de 27.000 bibliotecas e escolas, majoritariamente nos Estados Unidos, porém também com presença em outros países. Ao realizar empréstimos para bibliotecas públicas, o modelo de acesso que predomina é o de um livro eletrônico, um acesso, não sendo permitida a leitura simultânea do mesmo livro eletrônico por mais de um usuário. Oferece às bibliotecas flexibilidade de períodos de empréstimo, com variações de prazo de circulação entre 7, 14 ou 21 dias. Para realizar o leitura dos livros eletrônicos utiliza-se de plataforma proprietária (OverDrive Media Console ou OverDrive WIN) que valida a biblioteca assinante, seus usuários e as obras contratadas, que estão presentes no OPAC (Online Public Access Catalogue). Através dessa plataforma, o usuário pode realizar a leitura dos livros eletrônicos por computadores, tablets, e-readers ou smartphones. Também permite que os usuários realizem anotações nos livros eletrônicos consultados; a impressão parcial de trechos ou capítulos de obras é vinculada aos contratos definidos com cada editor (OVERDRIVE, 2011).

A Amazon, fundada em Seattle, Estado de Washington, em 1994, é uma empresa de comércio eletrônico que oferece livros (impressos e eletrônicos), música (cds, arquivos em mp3 etc.), vídeo, brinquedos, roupas, relógios, jogos, equipamentos e diversos outros produtos. Em 2007 lançou o dispositivo de leitura Kindle, considerado um marco no crescimento da oferta de livros eletrônicos no mercado. O e-reader, que utiliza formato proprietário (permite a leitura de livros eletrônicos nos formatos .mobi e .azw), firmou-se como uma opção para leitura de livros, jornais, revistas e demais recursos digitais. Até sua sexta geração (Kindle, Kindle 2, Kindle keyboard, Kindle Touch, Kindle Paperwhite, Kindle Paperwhite 2) utilizava-se do recurso de eInk (tinta eletrônica). Em 2013 foi lançado o modelo Kindle Fire, que apresenta tela de LCD e outras funcionalidades, saindo da configuração de e-reader para tablet. Atualmente o modelo Fire está em sua segunda geração (WIKIPEDIA, 2013).

Além da parceria com o OverDrive, a Amazon possui um programa próprio de empréstimo de livros eletrônicos, o Kindle Owners' Lending Library. Por meio desse 
programa os clientes da empresa podem tomar livros eletrônicos emprestados de forma gratuita. Os leitores podem emprestar um livro por mês, sem data para devolução. Outro título somente poderá ser consultado com a devolução do livro eletrônico emprestado. São oferecidos mais de 350.000 títulos para empréstimo. Essa modalidade de empréstimo é realizada apenas com proprietários de e-readers Kindle, independente do modelo, excluindo os leitores que se utilizam de tablets para realizar a leitura digital e, claramente, visa estimular a venda de dispositivos aos seus clientes (AMAZON, 2013).

\section{PARCERIA OVERDRIVE-AMAZON}

A parceria OverDrive-Amazon permite aos usuários de mais de 11.000 bibliotecas públicas e escolares norte-americanas o empréstimo de livros eletrônicos para e-readers Kindle ou tablets, computadores e smartphone que possuam aplicativo (APP) de leitura do Kindle para acessar livros eletrônicos nos formatos utilizados pela loja virtual (OVERDRIVE, 2013). O procedimento para utilização desse serviço inicia-se com a pesquisa do livro eletrônico no catálogo da biblioteca. Após a seleção de títulos no formato para Kindles, o usuário identifica-se como um leitor registrado através de seu cartão da biblioteca e indica o período de empréstimo que deseja, de acordo com o serviço oferecido e política de circulação estabelecida. Após a finalização deste processo, o usuário realiza o checkout e é transferido ao site da Amazon, onde completará a operação. Para utilizar o serviço, o usuário deve possuir uma conta na loja virtual, onde poderá realizar o download do livro emprestado. Depois que o usuário for identificado pela Amazon, o livro eletrônico estará disponível para leitura no equipamento informado pelo leitor. Ao faltar três dias para expirar o empréstimo, a Amazon enviará um e-mail notificando o usuário. Outra mensagem será encaminhada quando o período de empréstimo for finalizado (LIBRARY, 2011).

De acordo com Malczewski (2011), o OverDrive aproximou-se da Amazon com o intuito de melhorar sua ferramenta de leitura (WIN) com os conceitos estabelecidos pela empresa de comércio eletrônico, cujo foco sempre foi centrado na experiência do usuário. Uma das políticas da Amazon privilegia a experiência do consumidor, facilitando a encontrabilidade de produtos, a compra em apenas um clique e o armazenamento de informações, desde financeiras até de navegação, de seus clientes, identificando os temas de interesse, sugerindo e estimulando a compra de novos produtos. Seguindo essa abordagem, a parceria com a Amazon permitiu ao OverDrive mudanças em sua ferramenta, tornando a 
pesquisa e identificação das obras do catálogo mais amigáveis. Dessa forma o usuário não necessita informar os formatos de livros eletrônicos que deseja, bastando informar o modelo do equipamento que possui e a ferramenta disponibilizará somente as obras compatíveis com seu dispositivo. A preocupação do autor está centrada nos custos que podem advir dessa parceria, com o desenvolvimento da ferramenta WIN e, consequentemente, maiores custos às bibliotecas.

Porém, o que causou repercussão no mercado norte-americano não foi tanto o serviço de empréstimo de livros eletrônicos pela Amazon, mas o uso de informações dos usuários que a empresa começou a fazer. Enquanto a biblioteca e o OverDrive continuam mantendo as informações dos usuários como privadas e essas apenas são utilizadas para realizar as operações de empréstimo, a Amazon, por outro lado, agrega os dados das circulações realizadas, anotações etc. ao perfil do leitor, utilizando essas informações para divulgar ofertas e sugerir produtos para compra ou, até mesmo, para empréstimo através da biblioteca e da parceria com o OverDrive (UNDERSTANDING... 2011). Ao condicionar a utilização do serviço a vincular o registro da circulação com uma conta pessoal da Amazon, os usuários têm seus hábitos de leitura expostos e disponíveis para utilização pela loja virtual, afetando o compromisso de confiabilidade estabelecido por legislações estaduais e pelo próprio código de ética dos bibliotecários norte-americanos. A loja se reserva ao direito de encaminhar recomendações e sugestões de leitura, com base nas obras emprestadas ou compradas, atividade essa não realizada pelas bibliotecas, uma vez que elas não guardam as informações de circulações dos usuários, não incorrendo no erro de distribuir sem autorização, ao próprio usuário ou a terceiras partes, ou até mesmo ter informações furtadas por hackers (UNDERSTANDING, 2011). A loja também informa seus leitores que, ao comprarem os livros eletrônicos que foram emprestados nas bibliotecas, todas as anotações que foram feitas durante a circulação realizada pela Amazon serão automaticamente inseridas ao finalizar o processo de compra, fortalecendo a ideia que todas as informações, tanto da transação de empréstimo, como a leitura, navegação e anotações são armazenadas, compondo o perfil do cliente. O OverDrive publicou informações sobre sua política de confidencialidade, porém seu diretor, Steve Potash, admite que as informações de empréstimos, desde que não permitam identificação dos usuários, podem prover as bibliotecas de dados preciosos para conhecimento de seu público e adequação das obras e serviços prestados (KELLEY, 2013). 
O comércio eletrônico tem-se utilizado da ferramenta big data. Tendo o foco no armazenamento de dados e seu processamento em alta velocidade, o big data permite trabalhar com muitos dados simultaneamente, não se restringindo a amostragens, e deles retirar quaisquer informações que tenham aplicação ou que permitam a identificação de padrões de comportamento, consumo etc. Por abranger grande volume de dados, a massa de informações é expressiva, permitindo aos administradores a análise e tomadas de decisão decorrentes das observações realizadas. O big data é amplamente utilizado por empresas, favorecendo a expansão do comércio eletrônico ao coletar dados diversos - estruturados e não estruturados - e deles extrair informações que, quando voltadas ao negócio, podem fazer a diferença entre perdurar ou perecer, no disputado ambiente digital. Ao coletar, analisar e disseminar dados provenientes de diversas fontes, informações, tidas como de cunho pessoal e privado, passam a ser utilizadas como estratégias de marketing (MAYERSCHÖNBERGER; CUKIER, 2013).

O que convém analisar sobre essa parceria OverDrive-Amazon é a exposição dos dados e históricos de circulação e a coleta das informações dos usuários e os efeitos disso em relação à privacidade e confidencialidade (ou falta delas).

\section{PRIVACIDADE E CONFIDENCIALIDADE DOS DADOS DOS USUÁRIOS}

Desde a apresentação de informações de interesse dos usuários - a partir de registros de operações obtidos através de cookies, por histórico de navegações etc. -, os dados estão distribuídos na internet e disponíveis para aplicações diversas. As informações são coletadas em computadores, tablets, e-readers, smartphones, com empresas reunindo e monitorando as preferencias dos usuários, cruzando estas informações com outros dados produzidos por diferentes aparelhos, permitindo o desenho de um rastro digital dos passos dados pelas pessoas (ROMANI, 2013).

Nos Estados Unidos existem leis estaduais que controlam e preservam a confidencialidade dos usuários de bibliotecas. Essas legislações protegem desde o histórico de empréstimos realizados, até o uso de equipamentos disponíveis (computadores) nas bibliotecas. Dessa forma, os usuários de bibliotecas norte-americanas de alguns estados têm assegurado que seus empréstimos, hábitos de leitura ou demais usos de navegação na internet não serão rastreados, representando que a biblioteca é um local que credita 
confiabilidade. Essa medida é tomada considerando que monitorar o histórico de empréstimos ou navegação na internet realizados pelos usuários pode expô-los, causando constrangimentos. O governo norte-americano apenas intervém quando se detecta que existe risco de segurança nacional, justificando a solicitação de entrega de registros de operações realizadas pelas bibliotecas. Violações desta natureza foram registradas em ocasiões pontuais, como, por exemplo, na época do ataque às torres gêmeas, em 11 de setembro de 2001, ou em um episódio de 1983, quando a cidade do Estado de Iowa moveu ação para que a biblioteca divulgasse os nomes dos usuários que consultaram obras relacionadas ao tema bruxaria (KLIENFELTER, 2007, p.9). De acordo com Blitz (2006 apud KLIENFELTER, 2007, p.4), o valor da privacidade em bibliotecas é o direito de receber informações. Ao violar informações de uso dos usuários, teme-se que informações sejam analisadas fora de contexto, podendo ser mal interpretadas, gerando vigilância governamental, criação de perfil para informações de negócios (business data profiling) ou simplesmente expor a pessoa perante sua família, amigos e comunidade. Segundo o autor, a biblioteca deveria ser o local onde a informação pessoal está segura ou mantida em confidencialidade.

Evidentemente as leis apresentam variações nos 48 estados americanos que possuem um estatuto. Enquanto alguns estados não apresentam qualquer regulamento sobre o uso de dados pessoais, em outros, violar esse direito pode ser punido por multa (Michigan, Novo Mexico etc.), processo civil (Carolina do Sul, Flórida etc.), criminal (Carolina do Sul, Rhode Island etc.) ou até mesmo prisão (Carolina do Sul, Rhode Island etc.). Flórida e Kansas regulam a privacidade das obras emprestadas, assim como o Maine. Oklahoma e Carolina do Norte proíbem que qualquer acesso às informações dos usuários seja realizado (KLIENEFELTER, 2007, p.10). Os bibliotecários norte-americanos seguem os preceitos de código de ética, que estipula que proteger a privacidade e a confidencialidade é parte integral da missão das bibliotecas. A American Library Association (ALA) afirma o direito à privacidade desde 1939, com o Código de Ética do bibliotecário estabelecendo em seu $3^{\circ}$ artigo que:

"We protect each library user's right to privacy and confidentiality with respect to information sought or received, and resources consulted, borrowed, acquired or transmitted" (Nós protegemos o direito de cada usuário de biblioteca à privacidade $\mathrm{e}$ confidencialidade em relação a informação procurada ou recebida, e os recursos consultados, emprestados, adquiridos ou trasmitidos tradução nossa), (AMERICAN LIBRARY ASSOCIATION, 1986). 
Além do Código de Ética, os bibliotecários norte-americanos são encorajados a seguir os preceitos de privacidade da Library Bill of Rights, que garante o livre acesso aos recursos existentes nas bibliotecas e estabelece que:

"Protecting user privacy and confidentiality has long been an integral part of the mission of libraries" (Proteger a privacidade e confidencialidade do usuário é parte integral da missão das bibliotecas - tradução nossa), (AMERICAN LIBRARY ASSOCIATION, 2002).

Uma taxonomia da privacidade foi proposta por Daniel Solove (2006 apud KLIENEFELTER, 2007, p.3) identificando quatro tipos de ameaças: coleta, processo, disseminação e invasão de informação. As três primeiras estão relacionadas com retirar a informação do indivíduo, enquanto a última descreve atividades que interferem diretamente nele, caracterizando invasão ou decisão restritiva e que podem nem envolver informação. Segundo o autor, existem duas formas de ameaças de privacidade: uso indevido dos dados pessoais ou monitoramento das atividades pessoais. Bibliotecas públicas e seus serviços envolvem atividades que ameaçam (ou podem vir a ameaçar) a privacidade caso realizem coleta ou julgamento das obras consultadas por usuários, ou caso filtre ou limite o acesso à internet nos computadores locais da instituição. Os usuários de bibliotecas deixam informações pessoais a cada serviço utilizado. A pesquisa de uma obra no catálogo pode ser rastreada. As ações dos usuários podem ser coletadas, analisadas e utilizadas, inclusive, para fornecer novas informações de interesse aos usuários. O fato de coletar informações sobre obras consultadas ou a navegação da internet realizada de dentro da biblioteca pode resultar em invasão de privacidade de acordo com os preceitos de Solove. O limite entre utilizar as informações dos usuários pelas bibliotecas é especulativo e vago. Segundo Solove (2006 apud KLIENEFELTER, 2007, p.3), a ameaça de privacidade envolve a criação de um risco que pode ameaçar uma pessoa no futuro. De acordo com Westin (1967 apud KLIENFELTER, 2007, p.4), a esfera de proteção individual de comunicação pode dificultar o crescimento intelectual e espiritual, tanto por privar indivíduos como a sociedade democrática.

A ALA refere-se ao potencial mal uso de informações de leitura de usuários que consultam publicações sobre química, por exemplo, como se isso fosse uma evidencia que pretendem construir bombas. A utilização de tecnologia que permite rastrear as informações que foram utilizadas pelos usuários ou suas preferências pode vir a ferir estas normas de 
conduta dos bibliotecários (KLIENEFELTER, 2007, p.5). Miller (2013) enfatiza que a privacidade dos usuários das bibliotecas deve ser preservada e defendida pelos bibliotecários, destacando que eles devem ter o direito de pesquisar seus temas de interesse sem se preocuparem que estão sendo observados e seus gostos/pesquisas coletados e analisados. As bibliotecas norte-americanas são instituições que respeitam e privilegiam a privacidade e confidencialidade dos dados dos usuários e, nesse momento de superexposição de informações pessoais, devem continuar a proporcionar a segurança e privacidade.

$\mathrm{Na}$ Espanha também existe legislação específica acerca da proteção de dados pessoais. A Ley Orgânica 15/1999 e a Ley 34/2002 discorrem sobre a proteção de dados de caráter pessoal e serviços da sociedade de informação e de comércio eletrônico, respectivamente. Essas leis não discorrem especificamente sobre os dados dos usuários das bibliotecas, mas as instituições estão sujeitas a essa regulamentação. Dessa forma, as informações oriundas de empréstimos não são armazenadas, preservando apenas os dados necessários para realização das transações (MARTíN GAVILÁN, 2008).

Seguindo o modelo espanhol, Portugal também tem uma legislação sobre o tema (Lei 67, de 1998), seguindo a Diretiva do Parlamento Europeu e do Conselho n ${ }^{\circ}$ 95/46 CE, de 24 de outubro de 1995, que versa sore o tratamento dos dados pessoais e à livre circulação desses dados (PORTUGAL, 1998). Apesar de não citar textualmente as informações de usuários de bibliotecas, o $3^{\circ}$ artigo dessa lei discorre sobre:

“a) Dados pessoais: qualquer informação, de qualquer natureza e independentemente do respectivo suporte, incluindo som e imagem, relativa a uma pessoa singular identificada ou identificável; é considerada identificável a pessoa que possa ser identificada directa ou indirectamente, designadamente por referência a um número de identificação ou a um ou mais elementos específicos da sua identidade física, fisiológica, psíquica, económica, cultural ou social; b) Tratamento de dados pessoais: qualquer operação ou conjunto de operações sobre dados pessoais, efectuadas com ou sem meios automatizados, tais como a recolha, o registo, a organização, a conservação, a adaptação ou alteração, a recuperação, a consulta, a utilização, a comunicação por transmissão, por difusão ou por qualquer outra forma de colocação à disposição, com comparação ou interconexão, bem como o bloqueio, apagamento ou destruição;

c) Ficheiro de dados pessoais: qualquer conjunto estruturado de dados pessoais, acessível segundo critérios determinados, quer seja centralizado, descentralizado ou repartido de modo funcional ou geográfico;

d) Responsável pelo tratamento: a pessoa singular ou colectiva, a autoridade pública, o serviço ou qualquer outro organismo que, 
individualmente ou em conjunto com outrem, determine as finalidades e os meios de tratamento dos dados pessoais; sempre que as finalidades e os meios do tratamento sejam determinados por disposições legislativas ou regulamentares, o responsável pelo tratamento deve ser indicado na lei de organização e funcionamento ou no estatuto da entidade legal ou estatutariamente competente para tratar os dados pessoais em causa;

e) Subcontratante: a pessoa singular ou colectiva, a autoridade pública, o serviço ou qualquer outro organismo que trate os dados pessoais por conta do responsável pelo tratamento;

f) Terceiro: a pessoa singular ou colectiva, a autoridade pública, o serviço ou qualquer outro organismo que, não sendo o titular dos dados, o responsável pelo tratamento, o subcontratante ou outra pessoa sob autoridade directa do responsável pelo tratamento ou do subcontratante, esteja habilitado a tratar os dados;

g) Destinatário: a pessoa singular ou colectiva, a autoridade pública, o serviço ou qualquer outro organismo a quem sejam comunicados dados pessoais, independentemente de se tratar ou não de um terceiro, sem prejuízo de não serem consideradas destinatários as autoridades a quem sejam comunicados dados no âmbito de uma disposição legal;

h) Consentimento do titular dos dados: qualquer manifestação de vontade, livre, específica e informada, nos termos da qual o titular aceita que os seus dados pessoais sejam objecto de tratamento;

i) Interconexão de dados: forma de tratamento que consiste na possibilidade de relacionamento dos dados de um ficheiro com os dados de um ficheiro ou ficheiros mantidos por outro ou outros responsáveis, ou mantidos pelo mesmo responsável com outra finalidade.” (PORTUGAL, 1998).

Da mesma forma que na Espanha e demais países da Comunidade Européia, a legislação portuguesa engloba as bibliotecas em itens como o tratamento de dados pessoais (recolha, registro, organização, conservação, recuperação, consulta, utilização etc.), ficheiro de dados pessoais, responsável pelo tratamento, interconexão de dados etc.

No Brasil não existe, até o momento, legislação específica. O Ministério da Justiça colocou um anteprojeto de lei para debate público no período de novembro de 2010 a abril de 2011, que discorre sobre privacidade e proteção de dados. Esse anteprojeto foi encaminhado à Câmara e encontra-se em tramitação. Caso seja aprovado, irá complementar o Marco Civil da Internet, que é o principal projeto que visa regulamentar a privacidade de dados da internet no Brasil, que também aguarda votação. 


\section{INFORMAÇõES EM REDES SOCIAIS E PRIVACIDADE}

A biblioteca, ao ampliar seus serviços às redes sociais, também pode utilizar-se de informações distribuídas para identificar e conhecer seus usuários, promovendo ações que permitam a expansão dos serviços prestados. As principais redes sociais em ação nos EUA (Facebook e MySpace) são empresas que visam lucros e as informações pessoais são elementos que permitem a prospecção de dados que podem vir a gerar fontes de renda. De acordo com Lenhart ; Madden (2007 apud FERNANDEZ, 2009, p.2), 50\% dos jovens americanos possuem perfil no Facebook, repletos de informações pessoais como data de aniversário, gostos pessoais (músicas, passeios), dados de contato, amigos, familiares etc. Esses dados são utilizados pelas redes sociais para propaganda e divulgação de produtos que sejam compatíveis com o interesse do possuidor do perfil. Os usuários não se demonstram preocupados com sua própria privacidade e compartilham informações pessoais livremente nas redes (Acquisit ; Gross, 2006 apud FERNANDEZ, 2009, p.4). Também deve ser considerado que as redes sociais alteram seus perfis de privacidade de forma rápida e os bibliotecários não tem como controlar o uso da informação que é feito nesses ambientes, nem preservar os dados pessoais de seus usuários. As bibliotecas representam instituições confiáveis e não podem arriscar sua credibilidade ao permitir a apropriação de informação pessoal de seus usuários. Isso, porém, não pode ser utilizado como um artifício da biblioteca para não utilizar-se dessas ferramentas, até porque pode apresentar mais benefícios que danos (FERNANDEZ, 2009).

De acordo com Miller (2013), informações pessoais podem ser coletadas de pesquisas na internet, telefonemas, e-mails, textos e diversas outras formas de exposição. $\mathrm{O}$ caso recente da Agência de Segurança Nacional (NSA), com Edward J. Snowden levando a público, documentos que detalham a espionagem feita pela agência, demostrou que todas as pessoas estão vulneráveis de terem seus dados consultados ou utilizados, ressaltando que não apenas a agência norte-americana violou a privacidade, mas as próprias pessoas estão distribuindo seus dados em redes sociais, onde, ao exporem informações pessoais (fotografias, leituras e comentários gerais), também estão suscetíveis a propagandas e mudanças nas políticas de privacidade que nem sempre são claras ou divulgadas. Evidentemente existe distinção entre monitoramento governamental e rastreamento comercial, mas mudanças recentes nas buscas do Facebook tornou mais difícil ao usuário se 
esconder de desconhecidos. Empresas tem-se apoiado em redes de publicidade digital para desenvolver maneiras, cada vez mais sofisticadas, de rastrear consumidores, afinal são informações essenciais para a rentabilidade, uma vez que a publicidade seletiva - feita a partir de dados coletados na internet - é a principal fonte de renda de diversas empresas online (SENGUPTA, 2013). O que pensar, então de projetos que visam rastrear os passos de consumidores em locais públicos, independente de acesso ou distribuição de informações na internet? É o que pretende uma startup no Brasil, que se dispõe a oferecer às lojas físicas a utilização de dados coletados de forma automática - seções de lojas mais visitadas, frequência de visitas etc. -, através de sinais wi-fi de smartphones, fornecendo subsídios aos comerciantes para traçar perfis de seus consumidores para, assim, poderem oferecer novas possibilidades de produtos e serviços. Um teste semelhante foi realizado na rede de lojas Nordstrom, nos Estados Unidos, porém foi retirado quando as informações de rastreamento tornaram-se públicas, o que gerou críticas em relação à privacidade dos consumidores (FÁVERO, 2013).

As bibliotecas norte-americanas adotam questões éticas sobre informações pessoais de seus usuários, apesar de utilizarem as redes para divulgar novas obras e serviços disponíveis à comunidade. Excetuando a questão da privacidade do usuário, o uso de redes sociais é uma extensão das atividades desenvolvidas pelas bibliotecas. Segundo Fernandez (2009), é importante a biblioteca discutir o limite entre a ética relativa à privacidade dos usuários e o uso de redes sociais para divulgar as atividades desenvolvidas. Muitas bibliotecas estão utilizando as redes como instrumento de divulgação de seus trabalhos, muitas vezes por não possuírem orçamento para marketing. A aplicação pode tanto ser feita através de criação de perfis para interagirem com seus usuários com a criação de serviços avançados, como permitir a busca ao catálogo diretamente pela rede social (Farkas, 2007 apud FERNANDEZ, 2009, p.2).

Que não existe privacidade na internet, não é novidade. O que é novo é o uso que vem sendo feito de informações, muitas vezes colocadas pelas próprias pessoas, em redes sociais. Grandes empresas monitoram as redes, buscando distinguir perfis de usuários e, através desses, criar estratégias de atuação com o objetivo de realizar mais e mais transações comerciais. Será que não estamos presenciando a concretização do que foi vislumbrado por George Orwell, em sua novela 1984? Nesse romance, de 1949, a população encontra-se controlada pelo Big Brother, o Grande Irmão, que tudo vê, sabe e prevê. A partir do 
momento que as informações estão disponíveis a quem as consegue obter, coletar e extrair delas significado, a privacidade das pessoas é colocada em xeque. Pode-se também fazer um paralelo com a obra de Aldous Huxley, Admirável mundo novo, de 1932, que previa que a destruição da raça humana seria decorrente das coisas que o homem gosta ou lhe proporcionam prazer. No caso, a população era controlada por uma droga - soma - que não era nociva como as drogas habituais, mas tornava as pessoas dóceis e amáveis, não reagindo às diretrizes impostas pelo governo e fáceis de manipular. Se na obra de Orwell a população é manipulada por um estado controlador, Huxley propõe a destruição através daquilo que as próprias pessoas consomem e que vem a consumi-las (NAUGHTON, 2013; REVISTA BANG, 2013).

As redes sociais podem ser utilizadas como ferramentas de controle, ao permitir que os dados ali postados sejam coletados, analisados e retornados aos próprios usuários, mapeando comportamentos e atividades. Analisando as redes sociais pelo parâmetro das obras literárias citadas acima, elas podem tanto vir a ser uma ferramenta de controle quanto a concretização das ideias de Huxley, como uma droga, com as pessoas fornecendo informações de forma espontânea, que serão coletadas por empresas (e governos) e, dessa forma, serão controladas e alienadas. Mas a coleta de informações não precisa vir, necessariamente, de redes sociais. Essas são apenas mais uma opção de aplicação do big data. Outras ferramentas na internet proporcionam a coleta de informações diversas e essas, quando reunidas e analisadas, permitem a identificação das pessoas, padrões de comportamento e demais dados - estruturados e não estruturados - que favorecem a elaboração de perfis e definição de estratégias de marketing e venda por parte das empresas, visando identificar seus consumidores potenciais e oferecer produtos e serviços para eles, muitas vezes de forma personalizada.

\section{CONSIDERAÇÕES FINAIS}

Muito tem se falado sobre redes sociais e a utilização desses recursos pelas bibliotecas. Também se discute a questão do empréstimo de livros eletrônicos, na medida em que as ofertas de conteúdos digitais presentes nos acervos expandem-se. Que as redes sociais podem ser um canal de comunicação e interação dos usuários com as bibliotecas não resta a menor dúvida. Que deve ser explorado como um meio de disseminação de acervos e 
serviços prestados também é um consenso. Recomenda-se apenas que, ao utilizar-se de mecanismos automáticos que proporcionam melhor conhecimento do usuário e consequente prestação de serviços personalizados, a privacidade dos usuários e a confiabilidade das informações a eles inerentes não sejam prejudicadas, contribuindo com a manutenção do respeito mútuo e a credibilidade das instituições. O caso OverDrive-Amazon permite vislumbrar o uso de informações de usuários de bibliotecas públicas norte-americanas onde a privacidade e confidencialidade dos dados foram violados. As bibliotecas norteamericanas seguem legislações estaduais e o código de ética da American Library Association estabelece que as informações pessoais de usuários são preservadas e não distribuidas e que somente são utilizadas para realização de empréstimos e demais serviços bibliotecários. A Amazon, ao utilizar-se das informações que foram fornecidas de forma espontânea pelos leitores, não está agindo de forma ilegal, afinal os usuários da biblioteca forceceram seus dados à loja virtual que, a partir das informações de empréstimo, compras ou navegação realizados em seu site, estabelece um perfil desses usuários e divulga ofertas, lançamentos ou sugestões de aquisição. A repercussão do caso ocorreu em virtude das bibliotecas tomarem ciência do uso de informações privadas através de seus usuários, uma vez que nem as bibliotecas nem o OverDrive estavam cientes do uso de informações que a Amazon faria.

As bibliotecas podem (e devem) coletar dados de seus usuários com o intuito de oferecer serviços globais e personalizados, sugerir publicações relacionadas ao perfil dos leitores, realizar o DSI (Disseminação Seletiva da Informação), promover a divulgação de novas obras e, evidentemente, oferecer conteúdo digital, principalmente nos dias atuais, com a expansão de ensino à distância. Deve, porém, preocupar-se com a preservação dos dados dos usuários, garantindo a privacidade e confidencialidade deles, não distribuindo ou expondo essas informações. Mensurar o uso das publicações existentes nos catálogos possibilita a identificação do tipo de usuário que, alinhado com a missão da instituição, permite à biblioteca definir orientações para estabelecimento de políticas de desenvolvimento de coleções e serviços que serão oferecidos à comunidade. As informações decorrentes das transações realizadas nas bibliotecas sempre foram analisadas, mensuradas e utilizadas. O que difere atualmente é que as possibilidades de obtenção de dados foram ampliadas com a disponibilização de catálogos e serviços na internet, o uso de redes sociais e a própria interação com os usuários. 
As bibliotecas brasileiras não dispõem de regulamentações sobre a utilização de dados pessoais ou de privacidade de seus usuários. Com a aprovação dos projetos de lei que estão tramitando, elas deverão segui-los da mesma forma que as bibliotecas de Portugal, Espanha e demais países da Comunidade Europeia, ou seja, sem ter uma legislação específica, porém aderindo à normativa federal. O caso OverDrive-Amazon ainda não representa um problema às bibliotecas do Brasil. A Amazon iniciou sua loja brasileira no segundo semestre de 2013 e seu foco está centrado no aumento de comercialização do dispositivo de leitura Kindle. O OverDrive, até o momento, não atua comercialmente no país. A experiência, contudo, permite reflexão e aprendizado com as situações relatadas pelos bibliotecários norte-americanos, destacando a utilização de dados dos usuários ocorrida através de um procedimento de empréstimo de livro eletrônico realizado na biblioteca. Os livros eletrônicos ainda não estão presentes nas bibliotecas brasileiras de forma significativa. Instituições de ensino públicas e privadas já oferecem algum conteúdo licenciado, porém a baixa oferta de títulos em português, poucos fornecedores, altos preços dos dispositivos de leitura e o desconhecimento de possibilidades de utilização ainda são barreiras para sua inclusão. As bibliotecas públicas brasileiras tampouco estão adquirindo conteúdo digital, e esse, quando existente, está centrado em obras em domínio público ou de acesso aberto (open access). Conforme foi observado nos Estados Unidos e Europa, a inclusão de conteúdo digital licenciado iniciou-se pelas bibliotecas universitárias, expandindo-se às públicas, corporativas e escolares e essa tendência deve ocorrer no Brasil. As bibliotecas brasileiras podem aprender com as experiências de outros países evitando enfrentar os mesmos questionamentos como o ocorrido no caso OverDrive-Amazon. Observa-se a tendência de crescimento da oferta de livros eletrônicos nos acervos brasileiros e estar ciente da vulnerabilidade dos dados dos usuários deve ser analisado desde o primeiro momento, exigindo de fornecedores e parceiros a preservação do sigilo das informações dos usuários. 


\section{REFERÊNCIAS}

AMAZON. Kindle owners' lending library. Disponível em:

<http://www.amazon.com/gp/feature.html?/docld=1000739811>. Acesso em: 21 nov. 2013.

\section{AMERICAN LIBRARY ASSOCIATION. Code of ethics of the American Library}

Association. 2008. Disponível em:

<http://www.ala.org/advocacy/proethics/codeofethics/codeethics>. Acesso em: 4 nov. 2013.

Policy on confidentiality of library records. 02 jul. 1986. Disponível em:

$<$ http://www.ala.org/offices/oif/statementspols/otherpolicies/policyconfidentiality>. Acesso em: 04 nov. 2013.

An interpretation of the Library Bill of Rights. 19 jun. 2002. Disponível em: <http://www.ala.org/advocacy/intfreedom/librarybill/interpretations/privacy>. Acesso em: 19 nov. 2013.

FÁVERO, B. Rastreamento de clientes pelo celular chega a lojas do Brasil. Folha de São Paulo, São Paulo, 25 nov. 2013. Tec, p. 1-1. Disponível em:

<http://www1.folha.uol.com.br/tec/2013/11/1375267-rastreamento-de-clientes-pelo-celularchega-a-lojas-do-brasil.shtml>. Acesso em: 25 nov. 2013.

FERNANDEZ, P. Online social networking sites and privacy: revisiting ethical considerations for a new generation of technology. Library Philosophy and Practice (ejournal). Paper 246, 2009. Disponível em:

〈http://digitalcommons.unl.edu/libphilprac/246>. Acesso em: 5 nov. 2013.

JOHNSON, D. Libraries respond to Penguin, and it's not pretty. Disponível em: <http://www.mhpbooks.com/libraries-respond-to-penguin-and-its-not-pretty/>. Acesso em: 13 fev. 2012. 
KELLEY, M. Overdrive \& big (Private) data. Library Journal, 11 mar. 2013. Disponível em: <http://lj.libraryjournal.com/2013/03/opinion/editorial/overdrive-big-private-data/>. Acesso em: 24 nov. 2013.

KLIENEFELTER, A. Privacy and library public services: or, I know what you read last summer. Legal Reference Services Quarterly, v. 26, n.1/2, sept. 2007.

Disponível em: <http://ssrn.com/abastract=1011506>. Acesso em 9 nov. 2013.

LIBRARY EBOOKS FOR AMAZON KINDLE. Digital book downloads, 2011. (4 min.), son., color. Disponível em: 〈http://youtube.com/watch?v=mgKbyhuqxuU〉. Acesso em: 21 nov. 2013.

MALCZEWSKI, B. Amazon in overdrive: is there more to the overdrive/amazon deal than just the kindle? Journal of Electronic Resources Librarianship, v. 23, n. 4, p. 404-408, 2011. Disponível em: DOI: 10.1080/1941126X.2011.627813. Acesso em: 21 nov. 2013.

\section{MARTÍN GAVILÁN, C. Legislación española sobre protección de datos y su} implicación en la gestión bibliotecaria. 2008. Disponível em:

<http://eprints.rclis.org/14305/1/prodatos.pdf > . Acesso em: 11 nov. 2013.

MATZ, Chris. Libraries and the USA Patriot Act: values in conflict. Journal of Library Administration, v. 47, n.3/4, 2008, p. 69-87. Disponível em: <http://www.tandfonline.com/doi/abs/10.1080/01930820802186399\#.Un6nsfnH8Xi>. Acesso em: 9 nov. 2013.

MAYER-SCHÖNBERGER, V.; CUKIER, K. Big data: como extrair volume, variedade, velocidade e valor da avalanche de informação cotidiana. Rio de Janeiro: Campus, 2013.

MILLER, R. T. Protect thy patrons. Library Journal. Editorial, 1 oct. 2013. Disponível em: <http://lj.libraryjournal.com/2013/10/opinion/editorial/protect-thy-patrons-editorial/>. Acesso em: 24 nov. 2013. 
MISENER, D. HarperCollins sets checkout limits on library e-books. Disponível em: $<$ http://www.cbc.ca/news/technology/harpercollins-sets-checkout-limits-on-library-e-books1.992073>. Acesso em: 09 mar. 2011.

NAUGHTON, J. Aldous Huxley: the prophet of our brave new digital dystopia. The Guardian, London, 22 nov. 2013. Disponível em: < http://www.theguardian.com/commentisfree/2013/nov/22/aldous-huxley-prophet-dystopiacs-lewis>. Acesso em: 23 nov. 2013.

OverDrive: public libraries. Disponível em: <http://www.overdrive.com/libraries/publiclibraries/>. Acesso em: 21 nov. 2013.

\section{OverDrive and Amazon launch Kindle compability with library}

ebooks. Disponível em: <http://overdrive.com/news/overdrive-and-amazon-launch-kindlecompability-with-library-ebooks/>. Acesso em: 21 set. 2011.

PATTERN, D. I know what you borrowed last summer: exploiting usage data in an Academic Library. Disponível em: <daveyp.com/ili2009/>. Acesso em: 09 nov. 2013.

PORTUGAL. Lei nº 67, de 26 de janeiro de 1998. Transpõe para a ordem jurídica portuguesa a directiva 95/46/CE, do Parlamento Europeu e do Conselho, de 24 de outubro de 1995, relativa à protecção das pessoas singulares no que diz respeito ao tratamento dos dados pessoais e à livre circulação desses dados. Diário da República: $1^{\text {a }}$ Série A. 247. ed. p. 5536-5546. Disponível em: <http://www.cnpd.pt/bin/legis/nacional/lei_6798.htm>. Acesso em: 24 dez. 2013.

RANDOM HOUSE ELEVA PREÇOS DE E-BOOKS PARA BIBLIOTECAS. Disponível em: <http://www.publishnews.com.br/telas/noticias/detalhes.aspx?id=67352>. Acesso em: 05 mar. 2012.

REVISTA BANG. Admirável mundo novo. Disponível em: <http://revistabang.com/2013/11/22/admiravel-mundo-novo/>. Acesso em: 21 nov. 2013. 
ROMANI, B. Gigantes pensam em nova forma de saber o que você faz na web. Folha de

São Paulo, São Paulo. Tec, 18 nov. 2013. Disponível em:

$<$ http://www1.folha.uol.com.br/fsp/tec/139420-gigantes-pensam-em-nova-forma-de-sabero-que-voce-faz-na-web.shtml>. Acesso em: 18 nov. 2013.

SENGUPTA, S. A coleta de informações e seu paradoxo. Folha de São Paulo, São Paulo, 26 nov. 2013. The New York Times. Disponível em:

<http://www1.folha.uol.com.br/fsp/newyorktimes/140711-a-coleta-de-informacoes-e-seuparadoxo.shtml>. Acesso em: 26 nov. 2013.

\section{UNDERSTANDING LIBRARY EBOOK AND KINDLE LENDING, 21 nov. 2011.}

Disponível em: <http://beingruth.com/understanding-library-ebook-and-kindle-lending/>. Acesso em: 21 nov. 2013.

WIKIPEDIA. Disponível em: <http://en.wikipedia.org/wiki/Amazon.com>. Acesso em: 21 nov. 2013.

\section{Como citar este artigo:}

SERRA, Liliana Giusti. Empréstimo de livros eletrônicos, redes sociais e a proteção de dados dos usuários. Rev. digit. bibliotecon. cienc. inf., Campinas, SP, v.13, n.1, p.42-60, jan/abr. 2015. ISSN 1678-765X. Disponível em: <http://www.sbu.unicamp.br/seer/ojs/index.php/rbci>. Acesso em: 31 Jan. 2015. 